\title{
Validation and Comparison of Reference Genes for qPCR Normalization of Celery (Apium graveolens) at Different Development Stages
}

\section{OPEN ACCESS}

Edited by:

David Bryla,

U.S. Department of Agriculture, Agricultural Research Service, USA

Reviewed by:

María De La Luz Guerrero González, Universidad Autónoma de San Luis

Potosí, Mexico

Aída Araceli Rodriguez Hernandez, Instituto Potosino de Investigación

Científica y Tecnológica, Mexico

*Correspondence: Ai-Sheng Xiong xiongaisheng@njau.edu.cn

Specialty section:

This article was submitted to Crop Science and Horticulture, a section of the journal Frontiers in Plant Science

Received: 16 November 2015 Accepted: 29 February 2016 Published: 17 March 2016

Citation:

Li M-Y, Wang F, Jiang Q, Wang G-L, Tian $C$ and Xiong A-S (2016) Validation and Comparison of Reference Genes for QPCR Normalization of Celery (Apium graveolens) at Different Development

Stages. Front. Plant Sci. 7:313. doi: 10.3389/fpls.2016.00313
Meng-Yao Li, Feng Wang, Qian Jiang, Guan-Long Wang, Chang Tian and Ai-Sheng Xiong *

State Key Laboratory of Crop Genetics and Germplasm Enhancement, College of Horticulture, Nanjing Agricultural University, Nanjing, China

A suitable reference gene is an important prerequisite for guarantying accurate and reliable results in GPCR analysis. Celery is one of the representative vegetable in Apiaceae and is widely cultivated and consumed in the world. However, no reports have been previously published concerning reference genes in celery. In this study, the expression stabilities of nine candidate reference genes in leaf blade and petiole at different development stages were evaluated using three statistics algorithms geNorm, NormFinder, and BestKeeper. Our results showed that TUB-B, TUB-A, and UBC were the most reference genes among all tested samples. GAPDH represented the maximum stability for most individual sample, while the UBQ displayed the minimum stability. To further validate the stability of reference genes, the expression pattern of AgAP2-2 was calculated by using the selected genes for normalization. In addition, the expression patterns of several development-related genes were studied using the selected reference gene. Our results will be beneficial for further studies on gene transcription in celery.

Keywords: celery, reference gene, qPCR, gene expression, developmental stage

\section{INTRODUCTION}

Celery is widely cultivated as a vegetable crop in the world, and is rich in flavonoids, carotenoids, carbohydrate, and fibrin. During the plant development process, the physiological and morphological characteristics of celery have significant changes, which will affect the eating quality of leaf blade and petiole. In the last few years, high throughput sequencing technology has been widely used in celery research, for exploration gene transcriptional mechanism and regulation networks (Jiang et al., 2014a,b; Li et al., 2014a,b; Jia et al., 2015). These studies have identified many key genes that involved in lignin biosynthetic pathway during celery development stages (Jia et al., 2015). Another study indicated that some genes were associated with apigenin biosynthesis during celery leaf development (Yan et al., 2014). However, more regulatory networks during plant development are still waiting to be studied.

Abbreviations: $A C T I N$, actin gene; $E F-1 \alpha$, elongation factor- $1 \alpha$ gene; GAPDH, glyceraldehyde-3-phosphate dehydrogenase gene; $R A P 2$, ethylene response factor RAP2 gene; TBP, TATA-box binding protein gene; TUB- $A, \alpha$-tubulin gene; $U B C$, ubiquitin $C$ gene; $T U B-B, \beta$-tubulin gene; $U B Q$, polyubiquitin gene; qPCR, quantitative real-time reverse transcription PCR. 
Gene expression pattern reflects the tendency of gene expression regulation, and provides a novel insight into understand the biological functions of genes. qPCR is a reliable and rapid method to evaluate the expression level of target gene, especially has very sensitive detection ability for some low copy mRNAs (Heid et al., 1996; Bustin, 2000; Mackay, 2004). To exclude the errors in mRNA extraction quality, reverse amplification efficiency, and qPCR procedures, the reference genes are needed for data correction and standardization (Radonić et al., 2004; Dheda et al., 2005). An ideal reference gene should have a constant expression in various tissues and different experimental conditions (Dheda et al., 2004). However, to date, no absolute reference gene has been identified in plants or animals (Volkov, 2003; Derveaux et al., 2010). Some studies directly selected the common reference genes such as ACTIN, GAPDH, and TUB to normalize the target genes without evaluating the expression stability. However, these reference genes have significant differences under different experimental conditions (Kim et al., 2003; Yan et al., 2012). The unstable expression of reference genes may cause the deviation of final result. Other researches pointed that two or more reference genes should be needed to normalize (Vandesompele et al., 2002; Schmid et al., 2003). Some valid statistical software have been developed, such as geNorm (Vandesompele et al., 2002), Bestkeeper (Andersen, 2004), NormFinder (Pfaffl et al., 2004), to evaluate the stability of the candidate reference genes under specific experimental conditions.

Currently, several reliable reference genes have been reported in plants, and the stability of reference genes in different plant species are not completely consistent (Czechowski et al., 2005; Jiang et al., 2014a; Tian et al., 2015). ACT7 and PP2A genes displayed the maximum stability under abiotic stress conditions in Oenanthe javanica (Bl.) (Jiang et al., 2014a), ACTIN and TUB were the most stable genes in carrot (Tian et al., 2015). Moreover, the reference genes under different experimental conditions are also not the same. In the study of rice, eIF- $4 \alpha$ and ACT1 were the most suitable reference genes during seed development ( $\mathrm{Li}$ et al., 2010), UBQ5 and eEF-1 $\alpha$ were most stable across all the tissue samples (Jain et al., 2006), while the $18 S$ rRNA was the most reliable reference gene under various growth stages of etiolated seedlings and different cultivars (Kim et al., 2003). However, none of reference gene in celery has been reported. Hence, identification of suitable reference genes in various tissues and at different development stages will be required, which will greatly contribute accurate and reliable analysis of gene expression.

To accurately normalize the target gene expression in celery tissues and development stages, nine candidate reference genes were selected and their expression stability was evaluated. The target gene $A g A P 2-2$, a gene encoding an AP2/ERF transcription factor, was used to validate the selection of reference gene. In addition, the expression patterns of development-related genes were also analyzed using the selected reference gene. This study aims to identify the most suitable reference genes that will provide a more accurate and reliable expression analysis of other celery genes among various tissues and development stages.

\section{MATERIALS AND METHODS}

\section{Plant Materials and Growth Conditions}

The seeds of celery (Apium graveolens L. cv. Ventura) were cultivated in a controlled-environment growth chamber in Nanjing Agricultural University, China $\left(32^{\circ} 02^{\prime} \mathrm{N}, 118^{\circ} 50^{\prime} \mathrm{E}\right)$. All plants were grown under a photoperiod of $16 \mathrm{~h}$ with $300 \mu \mathrm{mol}$ $\mathrm{m}^{-2} \mathrm{~s}^{-1}$ light intensity at $25^{\circ} \mathrm{C}$ and $8 \mathrm{~h}$ dark condition at $16^{\circ} \mathrm{C}$. The relative humidity varied from 60 to $65 \%$. Three development stages of celery were evaluated, and the height of the plant at Stage 1 was $10 \mathrm{~cm}$ (35 d), the height of the plant at Stages 2 was $20 \mathrm{~cm}$ (50 d), and the height of the plant at Stages 3 was $30 \mathrm{~cm}$ (65 d; Figure 1). Three biological replicate samples of celery leaf blade and petiole at each developmental stage were collected, then immediately frozen in liquid nitrogen and stored at $-80^{\circ} \mathrm{C}$ until use.

\section{RNA Isolation and cDNA Synthesis}

Total RNA was extracted using the total RNA kit (Tiangen, Beijing, China) and then treated with RNase-free DNase I (Takara, Dalian, China) to eliminate genomic DNA contamination. The quantity and quality of RNA samples were measured by agarose gel electrophoresis and the use of a Nanodrop ND 1000 spectrophotometer (Nanodrop Technologies Inc., Delaware, USA). Only the samples with an $\mathrm{A}_{260} / \mathrm{A}_{280}$ ratio of $1.8-2.2$ and an $\mathrm{A}_{260} / \mathrm{A}_{230}$ ratio $>1.8$ were used for further analysis. Total RNA $(1.0 \mu \mathrm{g})$ was reverse-transcribed into cDNA using a PrimeScript RT reagent kit (Takara, Dalian, China). The cDNA was efficacy dilutions $\left(10 \mathrm{X}, 10^{2} \mathrm{X}, 10^{3} \mathrm{X}\right.$,

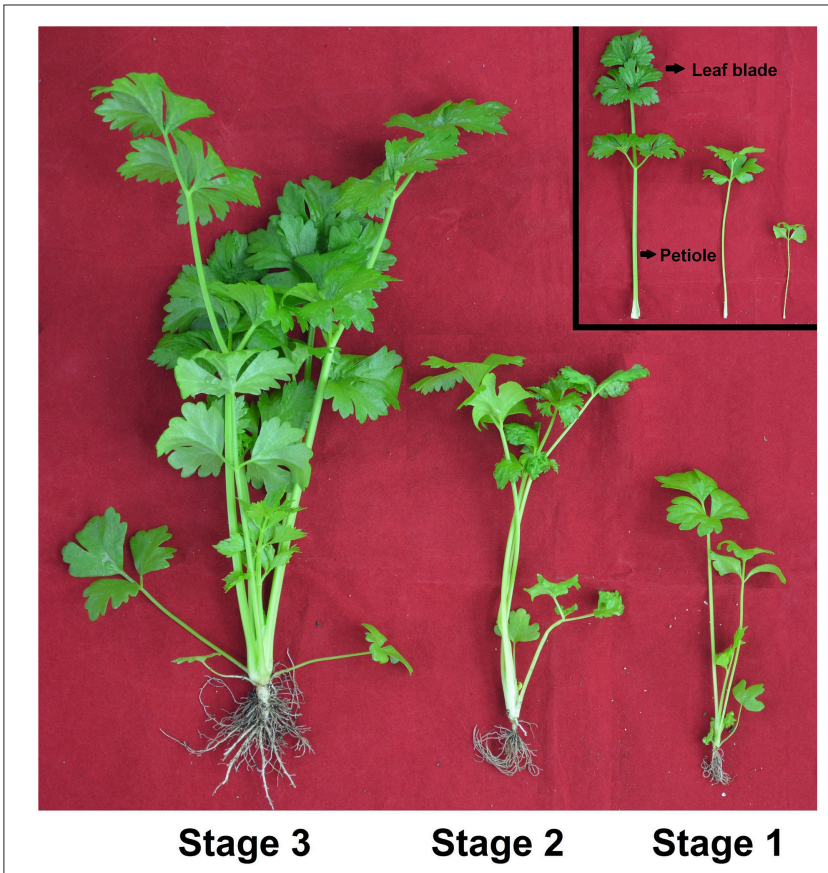

FIGURE 1 | Growth status of celery at three developmental stages. The leaf blades and petioles at different developmental stages were presented, respectively. Stage 1, 35 days after sowing; Stage 2, 50 days after sowing; Stage 3,60 days after sowing. 
$10^{4} \mathrm{X}, 10^{5} \mathrm{X}$ dilution) for detecting the amplification efficiency $(E)$ and correlation coefficient $\left(R^{2}\right)$, and 18 -fold dilution for qPCR experiments.

\section{Selection of Candidate Reference Genes and Primer Design}

Nine typical candidate reference genes of celery, ACTIN, EF$1 \alpha, G A P D H, R A P 2, T B P, T U B-A, U B C, T U B-B$, and UBQ, were selected for $\mathrm{qPCR}$ analysis in this study. Arabidopsis reference genes were downloaded from the TAIR database (http://www.arabidopsis.org) and used as query sequences to retrieve the homologs genes in celery. Based on the A. graveolens transcriptome sequencing data built by our group ( $\mathrm{Li}$ et al., 2014a; Jia et al., 2015), nine potential genes were cloned. We have submitted all the nucleotide sequences to GenBank, and the corresponding accession numbers were KU234487 (ACTIN), KU234488 (EF-1 $\alpha$ ), KU234489 (GAPDH), KU234490 (RAP2), KU234491 (TBP), KU234492 (TUB-A), KU234493 (UBC), KU234494 (TUB-B), and KU234495 (UBQ). The primers used for qPCR were designed by Primer Premier 6 using a standard set of design criteria (annealing temperatures $58-60^{\circ} \mathrm{C}$, primer lengths $18-26 \mathrm{bp}, \mathrm{GC}$ content between 40 and $60 \%$, and the PCR product between 60 and 150 bp; Udvardi et al., 2008). Primer sequences and amplicon characteristics are listed in Table $\mathbf{1 .}$

\section{qPCR and Statistical Analysis}

The qPCR reactions were performed in a 96 well plate using the MyiQ Single Color Real-Time PCR Detection System (Biorad, Hercules, CA, USA). Each $20 \mu \mathrm{L}$ PCR reactions contained $2.0 \mu \mathrm{L}$ of diluted cDNA, $0.4 \mu \mathrm{L}$ of each primer $(10 \mathrm{mM}), 10 \mu \mathrm{L}$ of SYBR Green I mix (Takara, Dalian, China), and 7.2 $\mu \mathrm{L}$ of dd $\mathrm{H}_{2} \mathrm{O}$. The PCR conditions were as follows: at $95^{\circ} \mathrm{C}$ for $30 \mathrm{~s}$ for predenaturation, 40 cycles of $95^{\circ} \mathrm{C}$ for $5 \mathrm{~s}$ for denaturation, and $60^{\circ} \mathrm{C}$ for $30 \mathrm{~s}$ for annealing and extension. A melting curve $\left(65-95^{\circ} \mathrm{C}\right.$, at increments of $0.5^{\circ} \mathrm{C}$ ) was generated to verify the specificity of primer amplification. Each PCR reaction was repeated three times, and three biological replicates were analyzed. In Addition, each assay contained a standard curve of different dilutions of the template and a no-template control. Amplification efficiency of each primer pair was calculated $\left(\% E=\left(-1+10^{[-1 / \text { slope }]}\right) \times\right.$ $100 \%)$ and correlation coefficient $\left(R^{2}\right)$ was tested.
Expression level of nine genes in each reaction was determined by the cycle threshold $\mathrm{Cq}$ (the cycle at which a threshold fluorescence was obtained). The original data was presented in the Table S1. Three different Microsoft Excel-based softwares, geNorm (Vandesompele et al., 2002), NormFinder (Andersen, 2004), and BestKeeper (Pfaffl et al., 2004), were used to determine the best reference genes. These raw data can be directly used for BestKeeper program, but for geNorm and NormFinder, Cqvalues were converted into relative quantity values by the formula $2^{-\Delta \mathrm{Cq}}, \Delta \mathrm{Cq}=$ the corresponding $\mathrm{Cq}$-value - minimum Cq.

(1) geNorm. In geNorm, the calculation principle relies on the expression ratio of two ideal internal control genes is identical in all samples. The gene expression stability measure $M$ is calculated as the level of pairwise variation for that gene compared with all other tested reference genes. geNorm identify these genes by progressively eliminating less stable genes from the analysis, and the reference gene with the lowest pairwise variation is the most stable. Besides, optimal number of multiple reference genes was determined by pairwise variation $\left(V_{n / n+1}\right)$ between normalization factors $\left(\mathrm{NF}_{n}\right.$ and $\left.\mathrm{NF}_{n+1}, n \geq 2\right)$ in geNorm.

(2) NormFinder. The NormFinder program ranks all candidate reference genes on the basis of intragroup and intergroup expression variations, and then combines them into a stability value for each candidate reference gene. This program can avoid the misinterpretations which caused by artificial selection of co-regulated genes. The reference gene with the lowest stability value is the most stable.

(3) BestKeeper. BestKeeper ranks the candidates' stability based on the standard deviation $(S D)$ and the coefficient of variation $(C V)$ with the $\mathrm{Cq}$-values of all genes. Candidate reference gene with the lowest $S D$ - and $C V$-values is considered as the most stable gene.

\section{Selection and Expression Analysis of Development Related Genes}

The transcriptome sequencing of three celery development stages were finished by our group ( $\mathrm{Li}$ et al., 2014a; Jia et al., 2015). Base on the annotation of celery genes, some of the genes were related to plant growth and development. Transcript abundances

TABLE 1 | Descriptions of candidate reference genes and primer sequences for qPCR.

\begin{tabular}{|c|c|c|c|c|c|}
\hline Gene & $\begin{array}{l}\text { Arabidopsis } \\
\text { homolog gene }\end{array}$ & Primer sequence $\left(5^{\prime}-3^{\prime}\right)$ & $\begin{array}{l}\text { Amplicon } \\
\text { size (bp) }\end{array}$ & $\begin{array}{l}\text { Annealing } \\
\operatorname{Tm}\left({ }^{\circ} \mathrm{C}\right)\end{array}$ & $\begin{array}{l}\text { Melting } \\
\operatorname{Tm}\left({ }^{\circ} \mathrm{C}\right)\end{array}$ \\
\hline ACTIN & AT5G09810 & AGAAGTCCTGTTCCAGCCGTCTT/CGAACCACCACTGAGCACTATGTT & 136 & 59.6 & 82.0 \\
\hline$E F-1 \alpha$ & AT1G07940 & GTCACCAGGAAGTGCCTCTGTAAG/TGTACCTGTCGGACGAGTTGAGA & 136 & 59.2 & 84.0 \\
\hline GAPDH & AT1G42970 & CAAGGACTGGAGAGGTGGAAGAG/GTGAGGTCAACAACTGAGACATCC & 159 & 57.9 & 83.5 \\
\hline RAP2 & AT1G53910 & GCTTATGATGCTGAGGCAAGGAGA/TGGTACAGAGCCGAACGAGAGT & 155 & 59.2 & 83.5 \\
\hline UBC & AT1G16890 & AGGCTTGAGATTCGCTGTCTGTAATATTCCTGGAGCTGGCTCACTGA & 158 & 59.3 & 81.5 \\
\hline$T U B-B$ & AT5G23860 & TGGTGGCACTGGATCTGGTATGG/ACTTCGGAGGAGGGAAGACTGAA & 105 & 59.5 & 80.0 \\
\hline$U B Q$ & AT4G05320 & GAAGATGGAAGAACTCTCGCAGAT/CGGTCAATGGTATCAGTTGGTTCA & 152 & 57.6 & 80.5 \\
\hline
\end{tabular}


were estimated by calculating read density as "reads per kilobase of exon model per million mapped reads" (RPKM; Mortazavi et al., 2008). The expression clusters of genes were analyzed by using Cluster (http://bonsai.hgc.jp/ mdehoon/software/cluster/ software.htm), and the heatmap was drawn using Tree View (http://jtreeview.sourceforge.net/).

qPCR was also performed to analyze the gene expression. Each reaction had three technical and biological repeats. The relative gene expression levels were calculated with the $2^{-\Delta \Delta C T}$ method (Pfaffl, 2001). The gene-specific primers are shown in Table S2.

\section{RESULTS}

\section{Amplification Specificity and Efficiency of Candidate Reference Genes}

The specific primers of nine candidate reference genes were designed for qPCR, with the amplicon length ranging from 105 to $159 \mathrm{bp}$. A single peak in the melting curve showed the expected amplification effect (Figure 2). The correlation coefficients $\left(R^{2}\right)$ and PCR amplification efficiencies of nine genes in leaf blade and petiole were calculated, respectively, the results met the standard $\left(R^{2}>0.99,90<E \%<110\right.$; Ramakers et al., 2003; Figures S1, S2).
The Cq-values in qPCR provided an overview of the gene expression levels of nine candidate reference genes in test samples. The transcript abundant for each gene has significant difference and the raw data were listed in Table S2. In general, the Cq-values between 18 and 30 are considered to be appropriate and effective data (Czechowski et al., 2005; Derveaux et al., 2010; Jiang et al., 2014a). In this study, all the Cq-values were between 17.03 and 29.84, and the mean Cq-values of the genes ranged from 21.57 for TUB- $A$ to 26.18 for TBP (Figure 3 and Table S3).

High Cq-value indicates the low expression levels, conversely mean the high expression. Among nine genes, GAPHD and TUB$A$ showed high expression with low Cq-values, whereas $U B C$ and $T B P$ showed low expression. The significant variation in gene expression indicated screening the appropriate reference gene should measure the stability.

\section{Stability of Candidate Reference Genes Under Different Development Stages and Tissues}

To select the most suitable reference gene, three methods (geNorm, NormFinder, and BestKeeper) were used to analyze the stability of each reference gene. The stability ranking of candidate reference genes in six individual samples were
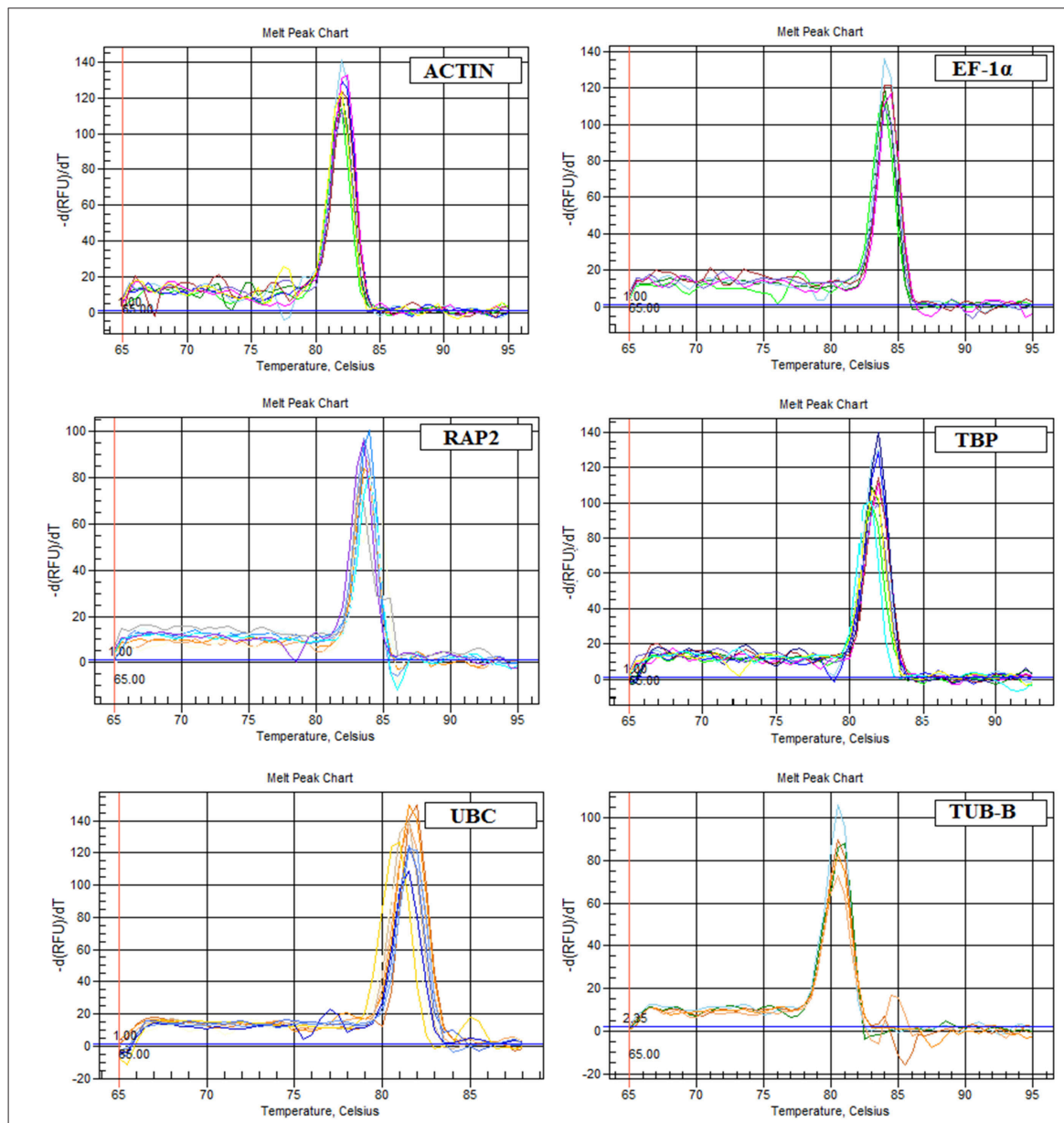
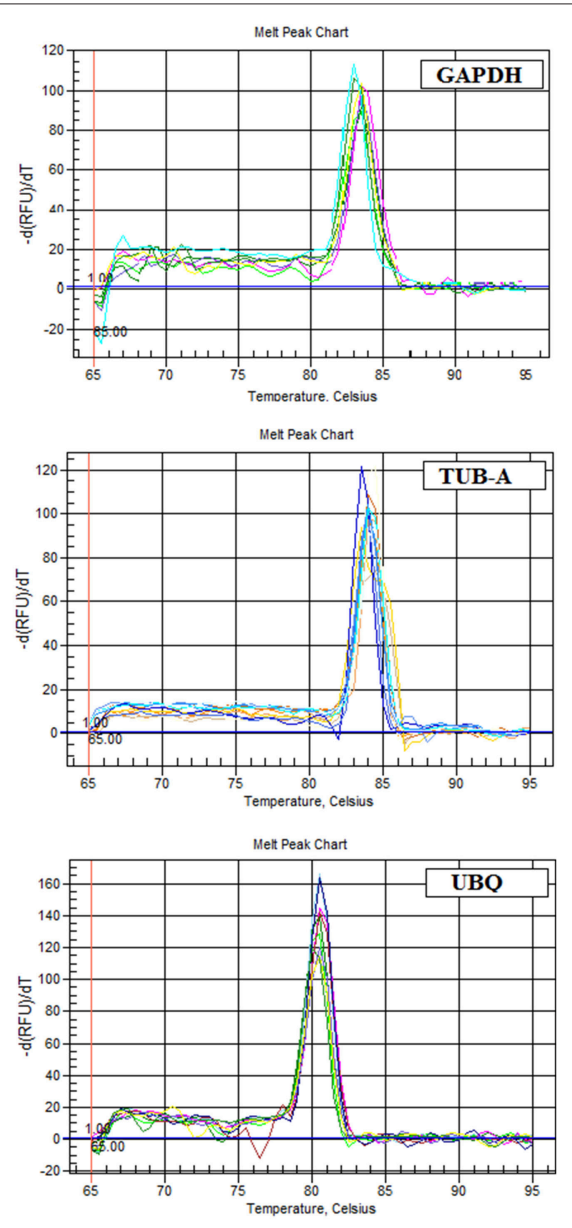

FIGURE 2 | Melting curves generated for nine candidate reference genes by qPCR. 


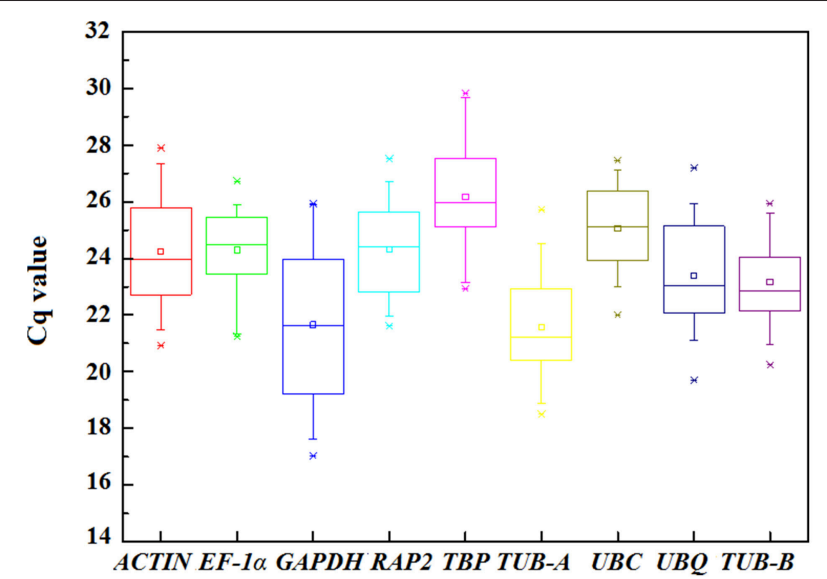

FIGURE 3 | Distribution of the Cq-values of the nine candidate reference genes across all samples in qPCR analysis. The straight line crossing the box depicts median and the inside box represent mean. The outside box indicates the 25th and 75th percentiles. Whiskers represent the 5th and 95th percentiles. Asterisk represents outlier.

calculated, respectively (Table 2). In addition, we divided these six samples into three groups: "Leaf blade," "Petiole," and "Total." For complexity of the groups, the ranks of the nine genes were calculated again and the results were shown in Table 3.

In geNorm analysis, the $M$-value was used to represent the average expression stability, the lower the $M$-value indicates a higher stability. In all six samples, the $M$-value of candidate reference genes were less than the default limit of 1.5 , but the most suitable reference gene was different in different tissues and development stages. GAPDH was the most stable gene at Stages 1 and 2 in leaf blade, and was the most stable gene at Stages 2 and 3 in petiole. $U B C$ exhibited relatively stable expression at Stage 3 in leaf blade and Stage 1 in petiole. Under all tissue sets, TUB- $B$ was the most stable gene among the nine candidate reference genes in "Leaf blade," "Petiole," and "Total," whereas UBQ was the least stable gene with the largest $M$-value in "Leaf blade" and "Total."

Another method, NormFinder, also classified TUB-B as the most stable reference gene with the minimum value of 0.005 at Stage 3 in leaf blade. GAPDH showed good stability at Stage 1 in leaf blade and at Stage 3 in petiole. However, GAPDH showed the worst stability at Stage 1 in petiole. In three groups, TUB- $B$ ranked first in "Leaf blade" and "Total" with the value of 0.051 and 0.117 , and ranked second in "Petiole" with the value of 0.163 . Moreover, UBQ was the most stable gene in "Petiole," but was the least stable gene in "Leaf blade" and "Total."

Based on calculations by BestKeeper software, the smaller SDand $C V$-value means the gene is more stable. BestKeeper ranked $T U B-A, R A P 2, U B C, U B Q, E F-1 \alpha, G A P D H$, respectively, as the best reference gene under three development stages in leaf blade and petiole. Although the best reference gene in six individual samples was not the same, $U B C$ had the lowest $S D$ - and $C V$ values in three groups. That meant $U B C$ was more stable than the other genes in three groups "Leaf blade," "Petiole," and "Total." At the same time, we also found that $U B Q$ had poor performance according to the ranking by BestKeeper.

\section{The Optimal Number of Reference Genes for Normalization in Celery}

The geNorm algorithm was used to determine the optimal number of reference genes by evaluating pairwise variation $\left(V_{n / n+1}\right)$ between normalization factors $\left(\mathrm{NF}_{n}\right.$ and $\mathrm{NF}_{n+1}, n \geq$ 2 ). The $V_{n / n+1}$-value below 0.15 suggested that an additional reference gene is not necessary for normalization (Vandesompele et al., 2002). Among the nine reference genes, the most stable reference genes varied in different samples and groups (Figure 4). For leaf blade development, two reference genes were enough for normalization at Stages 1 and 2, while four reference genes were needed at Stage 3 with the $V_{4 / 5}$-value dropping to 0.15 . At three petiole development stages, four, seven, and two reference genes were needed, respectively. For group "Leaf blade," five stable reference genes were proposed to be used. When the samples were analyzed as "Petiole" or "Total," it seems that all the $V$-values were higher than 0.15 .

\section{Validation of the Selected Reference Genes}

To validate the suitability of reference genes, five reference genes including two most stable reference genes $T U B-B$ and $T U B-A$, two less stable reference genes $U B C$ and $R A P 2$, and the least stable reference gene $U B Q$ were selected as calibrator. The relative expression levels of $A g A P 2-2$ were, respectively, calculated by using the selected reference genes. The homologous gene in Arabidopsis, AtAP2 (AT4G36920), which have been confirmed to play an important role in plant development (Jofuku et al., 1994; Liu et al., 2014). In our transcriptome data (Jia et al., 2015), the transcript abundances of AgAP2-2 were significantly different at three developmental stages. As illustrated in Figure 5, the expression patterns of $A g A P 2-2$ had a greater difference using different reference genes. When using the most stable reference genes $T U B-B$ and $T U B-A$, the expression patterns of AgAP2-2 were consistent, and the expression level was higher in petiole, especially at Stage 3. Similar expression patterns were generated by using the less stable reference genes $U B C$ and $R A P 2$. However, when the least stable reference gene $U B Q$ was used, the expression level of AgAP2-2 had a strong bias compared with other genes. This result demonstrated that the reference gene with stable expression was necessary to accurately normalize the expression of target gene.

\section{Expression Abundances of Development-Related Genes in Three Development Stages}

Many genes have been identified to play key roles in plant growth and development, such as transcription factor genes, hormonerelated genes, and genes encoding ribosomal proteins (Katagiri, 1992; Horiguchi et al., 2012; Saini et al., 2013). In Arabidopsis, lots of genes were identified to involve in development and multiple biological processes (Jofuku et al., 1994; Horiguchi et al., 2011; Köllmer et al., 2011). The high-throughput transcriptome sequencing of three celery development stages were finished by our lab and the annotation of celery genes showed many genes were involved in plant development (Jia et al., 2015). Basing on the transcriptome data in celery and 
TABLE 2 | The stability ranking of candidate reference genes in individual tissue sample by geNorm, NormFinder, and BestKeeper.

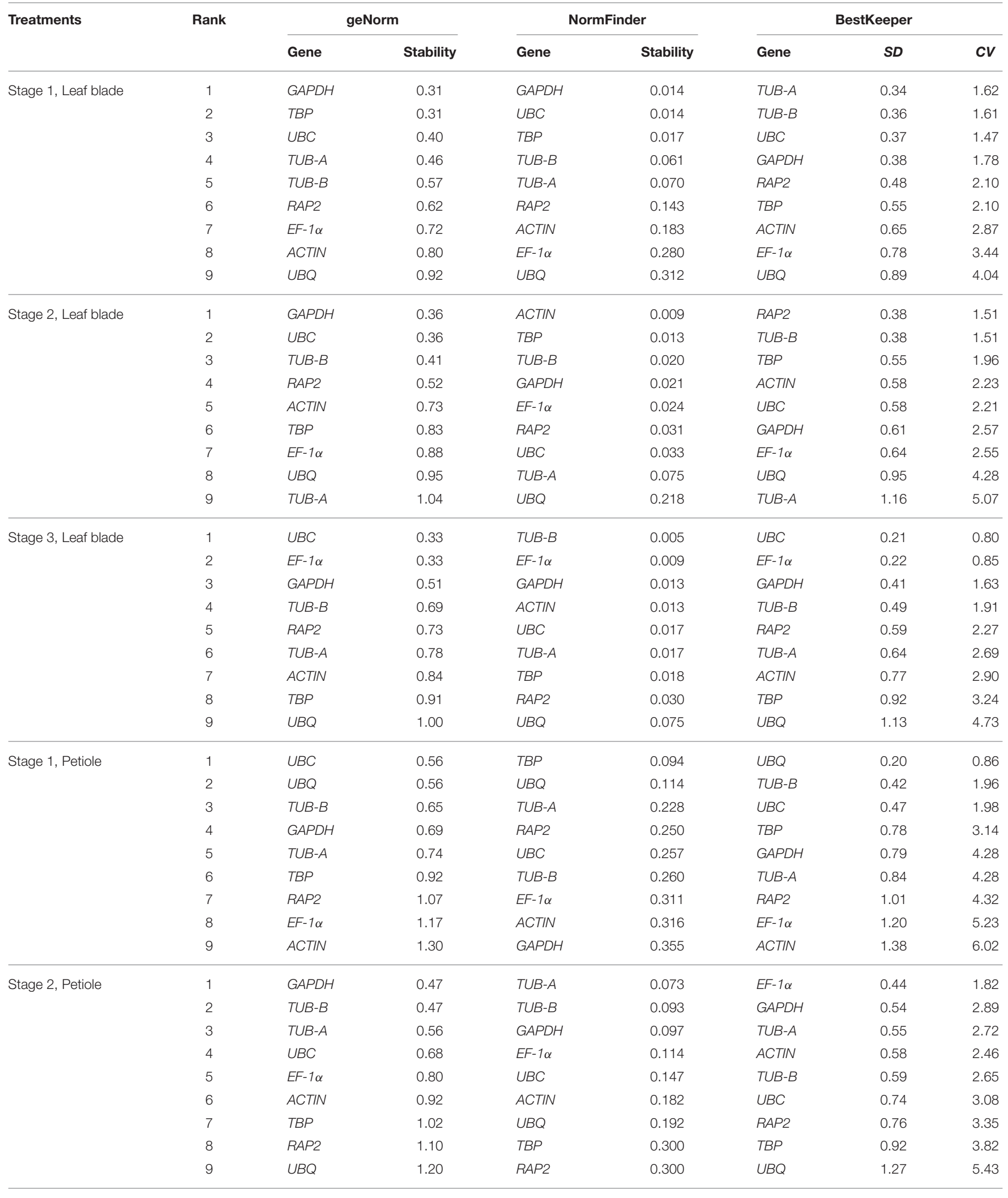


TABLE 2 | Continued

\begin{tabular}{|c|c|c|c|c|c|c|c|c|}
\hline \multirow[t]{2}{*}{ Treatments } & \multirow[t]{2}{*}{ Rank } & \multicolumn{2}{|c|}{ geNorm } & \multicolumn{2}{|c|}{ NormFinder } & \multicolumn{3}{|c|}{ BestKeeper } \\
\hline & & Gene & Stability & Gene & Stability & Gene & $S D$ & $C V$ \\
\hline \multirow[t]{9}{*}{ Stage 3, Petiole } & 1 & GAPDH & 0.42 & GAPDH & 0.010 & GAPDH & 0.29 & 1.33 \\
\hline & 2 & $T U B-A$ & 0.42 & $E F-1 \alpha$ & 0.015 & TBP & 0.31 & 1.22 \\
\hline & 3 & $T U B-B$ & 0.46 & $\cup B Q$ & 0.020 & TUB-A & 0.36 & 1.63 \\
\hline & 4 & $\cup B Q$ & 0.49 & TUB-A & 0.022 & $E F-1 \alpha$ & 0.42 & 1.64 \\
\hline & 5 & TBP & 0.54 & $T U B-B$ & 0.039 & $\cup B C$ & 0.42 & 1.72 \\
\hline & 6 & $\cup B C$ & 0.58 & RAP2 & 0.044 & TUB-B & 0.54 & 2.34 \\
\hline & 7 & $E F-1 \alpha$ & 0.68 & TBP & 0.056 & RAP2 & 0.65 & 2.55 \\
\hline & 8 & RAP2 & 0.80 & $\cup B C$ & 0.121 & $U B Q$ & 0.71 & 2.87 \\
\hline & 9 & ACTIN & 0.91 & ACTIN & 0.125 & ACTIN & 0.95 & 3.99 \\
\hline
\end{tabular}

$S D$, standard deviation; CV, coefficient of variation.

TABLE 3 | The stability ranking under "Leaf blade," "Petiole," and "Total” by geNorm, NormFinder, and BestKeeper.

\begin{tabular}{|c|c|c|c|c|c|c|c|c|}
\hline \multirow[t]{2}{*}{ Group } & \multirow[t]{2}{*}{ Rank } & \multicolumn{2}{|c|}{ geNorm } & \multicolumn{2}{|c|}{ Normfinder } & \multicolumn{3}{|c|}{ Bestkeeper } \\
\hline & & Gene & Stability & Gene & Stability & Gene & $S D$ & $C V$ \\
\hline \multirow[t]{9}{*}{ Leaf blade } & 1 & TUB-B & 0.47 & TUB-B & 0.051 & $\cup B C$ & 0.78 & 2.98 \\
\hline & 2 & RAP2 & 0.47 & $T U B-A$ & 0.054 & TBP & 0.96 & 3.48 \\
\hline & 3 & GAPDH & 0.74 & $U B C$ & 0.059 & $\cup B Q$ & 1.16 & 5.11 \\
\hline & 4 & $T U B-A$ & 0.81 & TBP & 0.066 & RAP2 & 1.21 & 4.89 \\
\hline & 5 & $\cup B C$ & 0.88 & GAPDH & 0.079 & $E F-1 \alpha$ & 1.24 & 5.11 \\
\hline & 6 & $E F-1 \alpha$ & 0.95 & RAP2 & 0.118 & TUB-B & 1.32 & 5.36 \\
\hline & 7 & TBP & 0.99 & ACTIN & 0.124 & TUB-A & 1.44 & 6.41 \\
\hline & 8 & ACTIN & 1.04 & $E F-1 \alpha$ & 0.192 & GAPDH & 1.61 & 6.84 \\
\hline & 9 & $\cup B Q$ & 1.16 & $\cup B Q$ & 0.226 & ACTIN & 1.66 & 6.61 \\
\hline \multirow[t]{9}{*}{ Petiole } & 1 & $T U B-B$ & 0.73 & $\cup B Q$ & 0.138 & $\cup B C$ & 0.75 & 3.11 \\
\hline & 2 & TUB-A & 0.73 & TUB-B & 0.163 & TBP & 0.86 & 3.45 \\
\hline & 3 & UBQ & 0.79 & TUB-A & 0.166 & TUB-B & 0.88 & 3.94 \\
\hline & 4 & $\cup B C$ & 0.84 & $U B C$ & 0.177 & ACTIN & 1.02 & 4.37 \\
\hline & 5 & GAPDH & 0.94 & $E F-1 \alpha$ & 0.201 & $E F-1 \alpha$ & 1.08 & 4.47 \\
\hline & 6 & $E F-1 \alpha$ & 1.07 & GAPDH & 0.209 & $T U B-A$ & 1.11 & 5.37 \\
\hline & 7 & TBP & 1.17 & ACTIN & 0.232 & $U B Q$ & 1.13 & 4.78 \\
\hline & 8 & RAP2 & 1.25 & TBP & 0.248 & RAP2 & 1.32 & 5.53 \\
\hline & 9 & ACTIN & 1.34 & RAP2 & 0.249 & GAPDH & 1.46 & 7.41 \\
\hline \multirow[t]{9}{*}{ Total } & 1 & TUB-B & 0.81 & TUB-B & 0.117 & $U B C$ & 1.13 & 4.52 \\
\hline & 2 & TUB-A & 0.81 & TUB-A & 0.128 & $E F-1 \alpha$ & 1.16 & 4.79 \\
\hline & 3 & $U B C$ & 0.87 & $U B C$ & 0.138 & $U B Q$ & 1.22 & 5.25 \\
\hline & 4 & TBP & 1.06 & GAPDH & 0.165 & RAP2 & 1.33 & 5.48 \\
\hline & 5 & RAP2 & 1.20 & ACTIN & 0.183 & TUB-A & 1.42 & 6.59 \\
\hline & 6 & $E F-1 \alpha$ & 1.30 & RAP2 & 0.192 & $T U B-B$ & 1.45 & 6.21 \\
\hline & 7 & ACTIN & 1.34 & TBP & 0.199 & TBP & 1.46 & 5.58 \\
\hline & 8 & GAPDH & 1.43 & $E F-1 \alpha$ & 0.209 & ACTIN & 1.59 & 6.56 \\
\hline & 9 & $U B Q$ & 1.57 & $U B Q$ & 0.241 & GAPDH & 2.14 & 9.87 \\
\hline
\end{tabular}

$S D$, standard deviation; $C V$, coefficient of variation.

the orthologous genes between celery and Arabidopsis, we selected 15 genes which, respectively, belonged to AP2/ERF transcription factor family, auxin-related gene, and ribosomal protein gene for further study. The expression abundances of these genes were analyzed by calculating the RPKMvalues.

As showed in Figure 6, the auxin-related genes (AgWAT1, $A g A B C B 19, A g S N X 1, A g A I L P 1, A g A R F 1)$ and ribosomal protein 


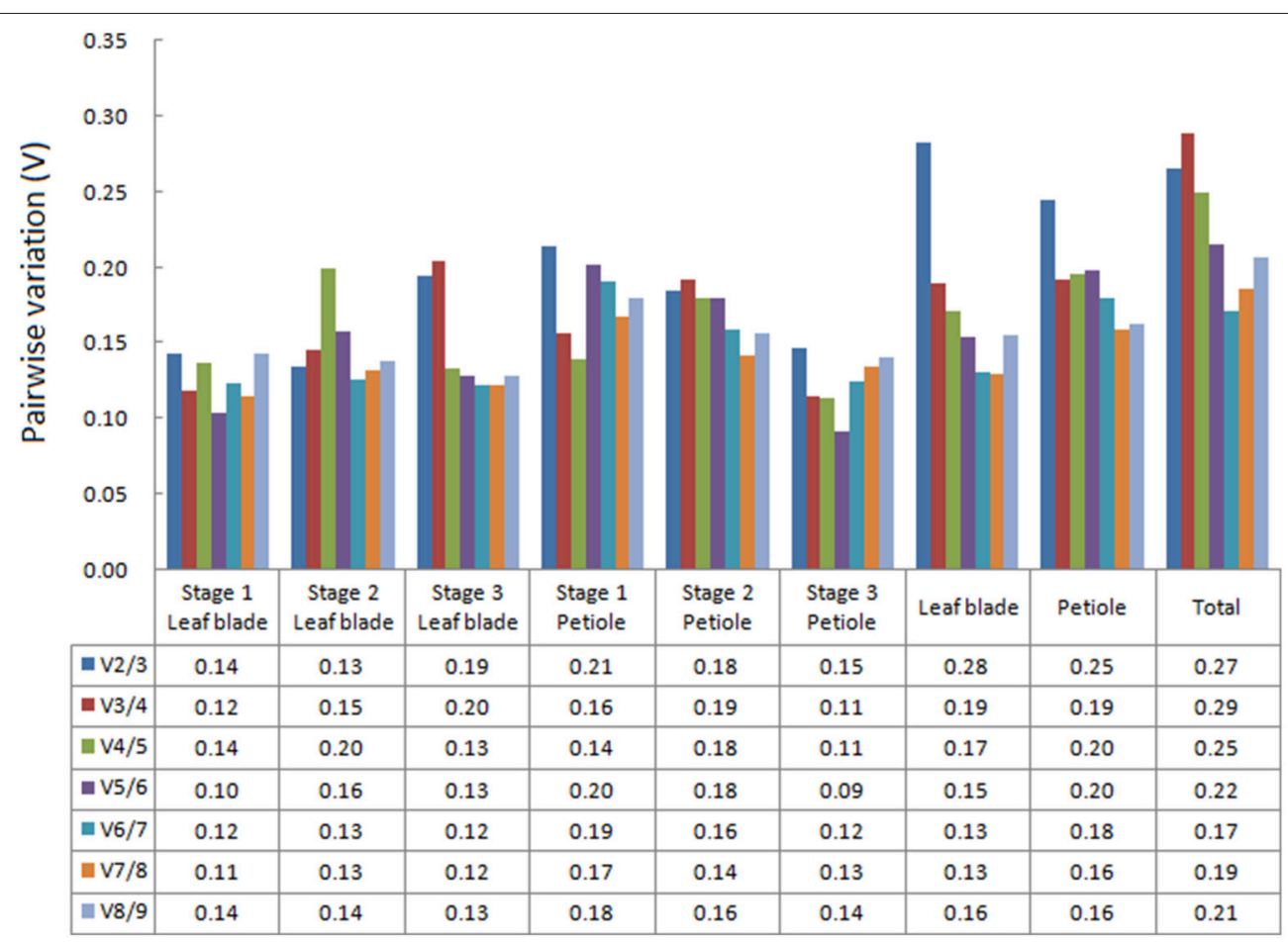

FIGURE 4 | Determination of the optimal number of reference genes. Pairwise variation $\left(V_{n} / n+1\right)$ were calculated between the normalization factors $\left(N F_{n}\right.$ and $\mathrm{NF}_{n+1}$ ) in all tested samples. The $V_{n / n+1}$-values below 0.15 suggested that an additional reference gene is not necessary for normalization.

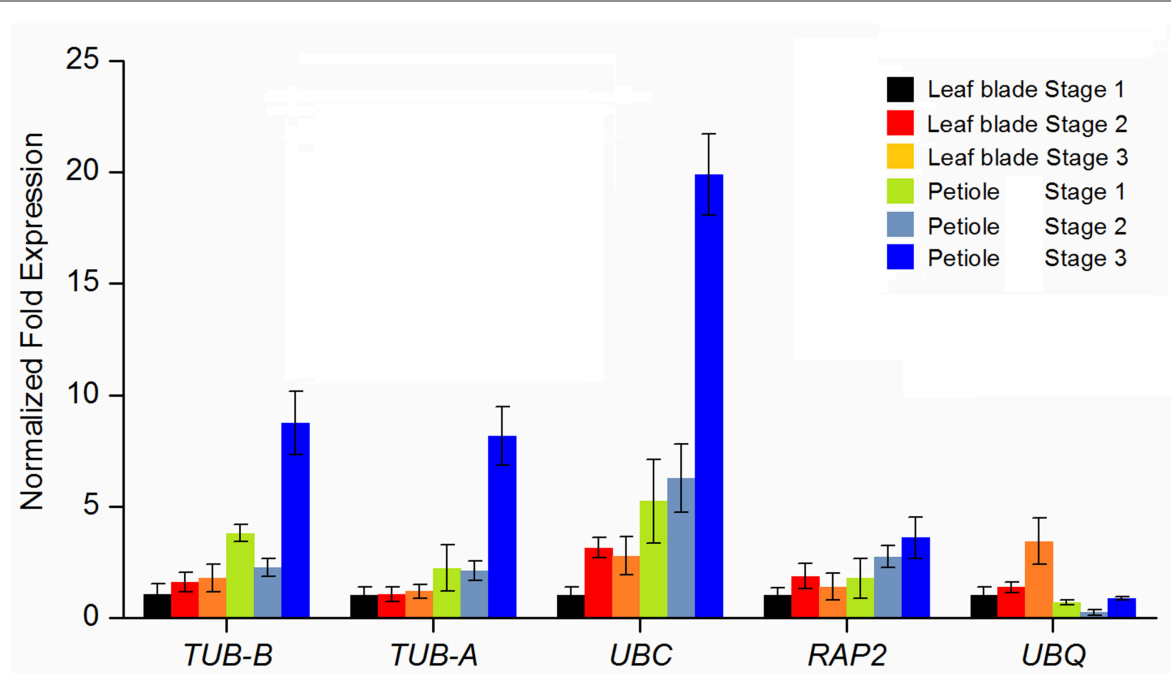

FIGURE 5 | Impact of different reference genes used for normalization on the relative quantification of $A g A P 2-2$ during leaf blade and petiole development. TUB- $B, T U B-A, U B C, R A P 2$, and $U B Q$ were used as reference gene for expression normalization.

genes (AgRPL24, AgRPS5, AgRPL15, AgRPL28, AgRPL27) have a relatively high abundance, whereas the AP2/ERF family genes (AgAP2-1, AgAP2-2, and AgANT belong to AP2 subfamily, AgRAP2 belongs to RAV subfamily, AgERF-4 belongs to ERF subfamily) were relatively low. Several genes which belonged to the same group showed a similar expression pattern, such as $A g W A T 1 / A g A I L P 1, A g A B C D 19 / A g A R F 1$, and $A g R P L 24 / A g R P L 27$. In addition, we also found that many genes showed differential expression at three development stages. Most AP2/ERF transcription factor genes and auxin-related genes showed low expression abundance at Stage1 and high abundance at Stages 2 and 3. It seemed that the expression of these genes 
A

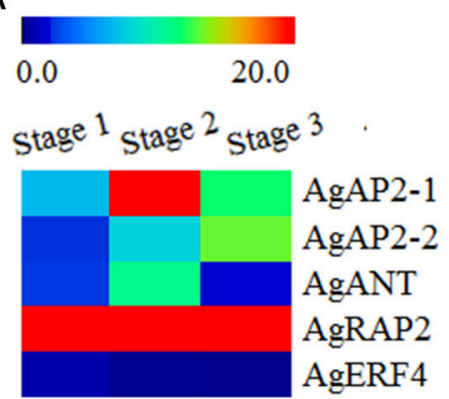

B

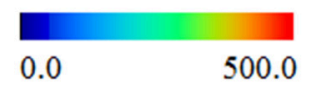

stage ${ }^{1}$ stage ${ }^{2}$ stage ${ }^{3}$
C

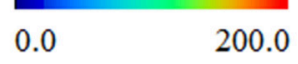

stage ${ }^{1}$ stage 2 stage 3

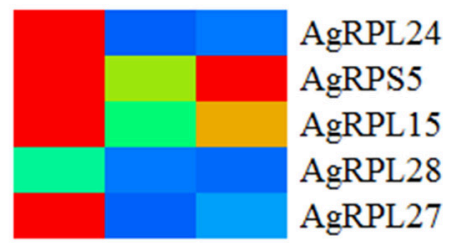

FIGURE 6 | Heatmap clustering of development-related genes expression abundances in three development stages. (A) Transcript abundances of AP2/ERF family genes. (B) Transcript abundances of auxin-related genes. (C) Transcript abundances of ribosomal protein genes. RPKM-values were log 2 -based. Red and blue indicate high and low expression levels, respectively.

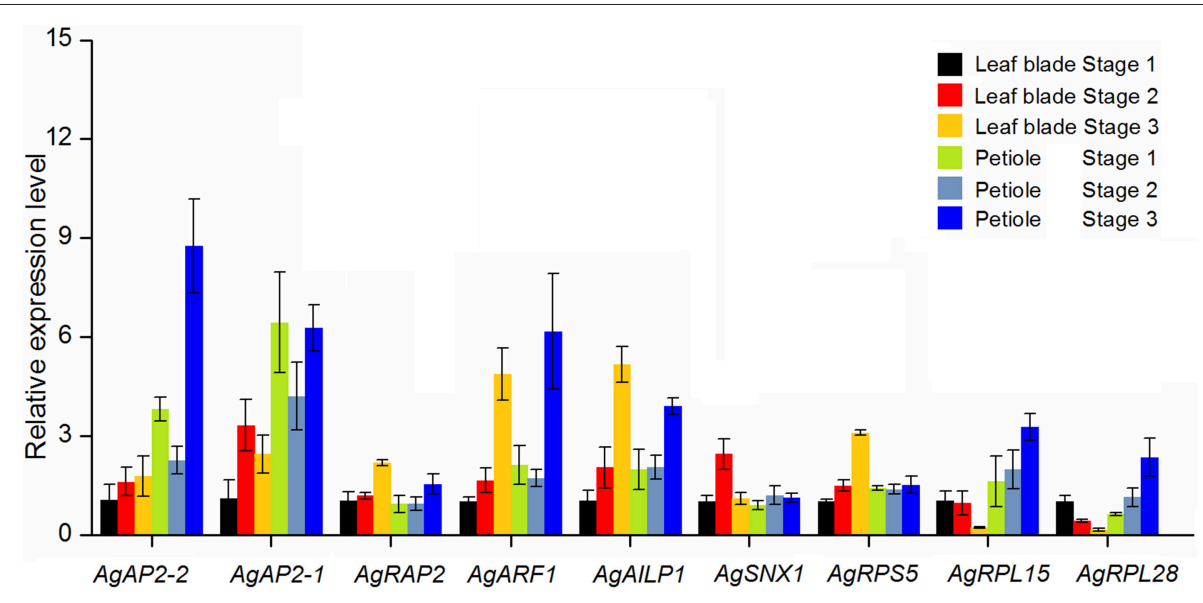

FIGURE 7 | qPCR analysis of the different expression genes in celery leaves blade and petioles at different developmental stages. TUB- $B$ was used as reference gene for expression normalization. The data are presented as the mean $\pm S D$ of three biological and technical replicates.

increased over the process of plant development. In contract, the expression levels of all the ribosomal protein genes at Stage 1 were significantly higher than those at Stages 2 and 3.

\section{qPCR Analysis of Different Expression Genes in Three Development Stages}

Among the selected genes, nine different expression genes were further selected to examine their expression levels in leaf blade and petiole at three development stages by qPCR (Figure 7). $T U B-B$ was used as control gene to normalize the expression. The expression patterns of AgAP2-1 and AgAP2-2 were similar: the expression level was higher in petiole, especially at Stage 3. Overall, the expression of these two genes increased with the plant development. AgRAP2 had a little change in leave blade and petiole at three stages, yet the expression abundance kept a high level in Figure 5. The two auxin-related genes, AgARF1 and $A g A I L P 1$, also showed the similar expression pattern: the expression differences were not significant between Stages 1 and 2 , but at Stage 3 the expression level increased about five times both in leaf and petiole. The other gene AgSNX1 seemed to have a stable expression. For the three ribosomal protein genes, the expression level of AgRPS5 in leaf blade had a slight increase, while in petiole showed no remarkable difference. Transcriptome data showed that this gene was detected with high abundance in three development stages (Figure 5). Interesting, the expression patterns of AgRPL15 and AgRPL28 in leaf blade were significantly decreased during the development of the leave blades, while the expressions in petiole were gradually increased.

\section{DISCUSSION}

qPCR has become an important tool for molecular biology research. Using a suitable reference gene can efficiently correct the errors of RNA quantity and reverse transcription efficiency, which can help to obtain the real differential expression of target gene (Udvardi et al., 2008). The most commonly used reference genes, which used as basic component of organelles skeleton ( $A C T I N, T U B-A$, and $T U B-B$ ) or involved in biochemical metabolic processes of organisms (GAPDH, EF-1 $\alpha$, and $U B Q$ ), can stably express in tissues and organs (Huggett et al., 2005; 
Gutierrez et al., 2008). However, recent studies have found that these reference genes may show instability under various plant species or genotypes (Wang et al., 2014, 2015). For example, GAPDH showed the most stability in grapevine but ranked worst in wheat (Reid et al., 2006; Long et al., 2010); $U B I$ and ACT showed good stability in wheat, yet performed unsatisfactory in tomato (Long et al., 2010; Mascia et al., 2010). Moreover, the expression stabilities of reference genes have been demonstrated to vary under different tissues and environmental stresses (Czechowski et al., 2005; Libault et al., 2008).

Since a large sequence data have been obtained in celery, the expression patterns and function analysis of many genes will be more convenient. As the vegetative organs, leaf blades and petioles are the product of specific development stage of celery. Previous study have revealed several key genes contribute to the complex network of celery development (Jia et al., 2015), further study involving the expression patterns and function analysis of these genes in various tissues and tissues developmental stages will be needed. To ensure accurate and reliable results, reference genes should be evaluated in target conditions. To date, there is no report on the selection of the most suitable reference genes in celery.

Three commonly used algorithms (geNorm, NormFinder, and BestKeeper) were used to evaluate and identify suitable reference genes (Vandesompele et al., 2002; Andersen, 2004; Pfaffl et al., 2004). In our study, geNorm ranked $T U B-B, T U B-A, U B C$ as the best reference genes. NormFinder generated a similar ranking to the geNorm analysis. BestKeeper recommended $U B C, E F-1 \alpha$, and $U B Q$ as the most stable reference genes under all samples. Taken all the results into consideration, $T U B-B, T U B-A$, and $U B C$ can be used as reference for normalization in celery development. ACTIN is always considered as a suitable reference gene, but the results of the current study indicated that ACTIN is not the best suitable reference gene in celery. The tubulin gene family members, including $T U B-A$ and $T U B-B$, also often serve as the suitable candidate reference genes. The expression stability of $T U B-A$ is generally higher than the $T U B-B$ (Brunner et al., 2004; Jian et al., 2008). But in this study, TUB-B appears to be more stable. Using a single reference gene for calibration and standardization is deemed to affect the accuracy of the result (Zhu et al., 2008). Schmid et al. (2003) suggested that two or more reference genes can contribute to the calibration of system deviation under a set of samples or experimental conditions. The geNorm programmer determined the optimal number of reference genes necessary for normalization under different samples in our study. With a threshold of 0.15 , two reference genes were enough for normalization at Stages 1 and 2 in leaf blade and at Stage 3 in petiole, while more genes were needed for other tissue or conditions. In "Petiole" and "Total" groups, there was no suitable number of reference genes. The complexity of the samples may result in higher variability. However, using more reference genes can help to reach possible optimum results, but not a necessary criterion (Vandesompele et al., 2002).

A large number of genes are involved in the process of plant development. Some transcription factors, such as AP2/ERF, NAC, MADS-box, participated in cell differentiation, organ development, and construction of plant morphology (Rounsley et al., 1995; Köllmer et al., 2011; Le et al., 2011). In this study, genes encoding AP2/ERF family transcription factors expressed differently at different stages of celery development, suggested that these genes might involve in activity developmental regulation in celery. The expression levels of auxin-related genes and ribosomal protein genes were relatively high, especially the expressions of several ribosomal protein genes in early development stage. With the exuberant cell division activity, the young leaves require a lot of protein synthesis to meet the growing needs. The high expression of ribosomal protein genes in the initial stage of plant growth provides a prerequisite for translating other development-related genes. Some of the ribosomal protein genes associated with leaf development in Arabidopsis were also confirmed (Schippers and MuellerRoeber, 2010). Overall, the coordinated regulation of a large number of development related genes has realized normal development of plants. Selection of the suitable reference genes provides a favorable basis for the further research on celery development.

\section{AUTHOR CONTRIBUTIONS}

AX and ML conceived and designed the experiments. ML, GW, QJ, CT, and FW performed the experiments. ML, QJ, CT, and AX analyzed the data. AX contributed reagents/materials/analysis tools. ML wrote the paper. ML and AX revised the paper.

\section{ACKNOWLEDGMENTS}

The research was supported by the National Natural Science Foundation of China (31272175); Jiangsu Natural Science Foundation (BK20130027); and Priority Academic Program Development of Jiangsu Higher Education Institutions.

\section{SUPPLEMENTARY MATERIAL}

The Supplementary Material for this article can be found online at: http://journal.frontiersin.org/article/10.3389/fpls.2016. 00313

Figure S1 | Standard curves of each candidate genes in leaf blades.

Figure S2 | Standard curves of each candidate genes in petiole.

Table S1 | Raw Cq-values of candidate reference genes.

Table S2 | Oligonucleotide primer sequences.

Table S3 | Data statistics of Cq-values of candidate reference genes in all samples. 


\section{REFERENCES}

Andersen, C. L. (2004). Normalization of real-time quantitative reverse transcription-PCR data: a model-based variance estimation approach to identify genes suited for normalization, applied to bladder and colon cancer data sets. Cancer Res. 64, 5245-5250. doi: 10.1158/0008-5472.CAN-04-0496

Brunner, A. M., Yakovlev, I. A., and Strauss, S. H. (2004). Validating internal controls for quantitative plant gene expression studies. BMC Plant Biol. 4:14. doi: 10.1186/1471-2229-4-14

Bustin, S. A. (2000). Absolute quantification of mRNA using real-time reverse transcription polymerase chain reaction assays. J. Mol. Endocrinol. 25, 169-193. doi: 10.1677/jme.0.0250169

Czechowski, T., Stitt, M., Altmann, T., Udvardi, M. K., and Scheible, W. R. (2005). Genome-wide identification and testing of superior reference genes for transcript normalization in Arabidopsis. Plant Physiol. 139, 5-17. doi: 10.1104/pp.105.063743

Derveaux, S., Vandesompele, J., and Hellemans, J. (2010). How to do successful gene expression analysis using real-time PCR. Methods 50, 227-230. doi: 10.1016/j.ymeth.2009.11.001

Dheda, K., Huggett, J. F., Bustin, S. A., Johnson, M. A., Rook, G., and Zumla, A. (2004). Validation of housekeeping genes for normalizing RNA expression in real-time PCR. Biotechniques 37, 112-119. doi: 10.2144/3701A0112

Dheda, K., Huggett, J. F., Chang, J. S., Kim, L. U., Bustin, S. A., Johnson, M. A., et al. (2005). The implications of using an inappropriate reference gene for real-time reverse transcription PCR data normalization. Anal. Biochem. 344, 141-143. doi: 10.1016/j.ab.2005.05.022

Gutierrez, L., Mauriat, M., Pelloux, J., Bellini, C., and Van Wuytswinkel, O. (2008). Towards a systematic validation of references in real-time RT-PCR. Plant Cell 20, 1734-1735. doi: 10.1105/tpc.108.059774

Heid, C. A., Stevens, J., Livak, K. J., and Williams, P. M. (1996). Real time quantitative PCR. Genome Res. 6, 986-994. doi: 10.1101/gr.6.10.986

Horiguchi, G., Mollá-Morales, A., Pérez-Pérez, J. M., Kojima, K., Robles, P., Ponce, M. R., et al. (2011). Differential contributions of ribosomal protein genes to Arabidopsis thaliana leaf development. Plant J. 65, 724-736. doi: 10.1111/j.1365-313X.2010.04457.x

Horiguchi, G., Van Lijsebettens, M., Candela, H., Micol, J. L., and Tsukaya, H. (2012). Ribosomes and translation in plant developmental control. Plantence 191-192, 24-34. doi: 10.1016/j.plantsci.2012.04.008

Huggett, J., Dheda, K., Bustin, S., and Zumla, A. (2005). Real-time RT-PCR normalisation; strategies and considerations. Genes Immun. 6, 279-284. doi: $10.1038 /$ sj.gene.6364190

Jain, M., Nijhawan, A., Tyagi, A. K., and Khurana, J. P. (2006). Validation of housekeeping genes as internal control for studying gene expression in rice by quantitative real-time PCR. Biochem. Biophys. Res. Commun. 345, 646-651. doi: 10.1016/j.bbrc.2006.04.140

Jia, X. L., Wang, G. L., Xiong, F., Yu, X. R., Xu, Z. S., Wang, F., et al. (2015). De novo assembly, transcriptome characterization, lignin accumulation, and anatomic characteristics, novel insights into lignin biosynthesis during celery leaf development. Sci. Rep. 5:8259. doi: 10.1038/srep08259

Jian, B., Liu, B., Bi, Y., Hou, W., Wu, C. X., and Han, T. (2008). Validation of internal control for gene expression study in soybean by quantitative real-time PCR. BMC Mol. Biol. 9:59. doi: 10.1186/1471-2199-9-59

Jiang, Q., Wang, F., Li, M. Y., Ma, J., Tan, G. F., and Xiong, A. S. (2014a). Selection of suitable feference genes for qPCR normalization under abiotic stresses in Oenanthe javanica (BI.) DC. PLoS ONE 9:e92262. doi: 10.1371/journal.pone.0092262

Jiang, Q., Wang, F., Li, M. Y., Tan, H. W., Ma, J., and Xiong, A. S. (2014b). Highthroughput analysis of small RNAs and characterization of novel microRNAs affected by abiotic stress in a local celery cultivar. Sci. Hortic. 169, 36-43. doi: 10.1016/j.scienta.2014.02.007

Jofuku, K. D., den Boer, B. G., Van Montagu, M., and Okamuro, J. K. (1994). Control of Arabidopsis flower and seed development by the homeotic gene APETALA2. Plant Cell 6, 1211-1225. doi: 10.1105/tpc.6.9.1211

Katagiri, F. (1992). Plant transcription factors, present knowledge and future challenges. Trends Genet. 8, 22-27. doi: 10.1016/0168-9525(92)90020-5

Kim, B. R., Nam, H. Y., Kim, S. U., Kim, S. I., and Chang, Y. J. (2003). Normalization of reverse transcription quantitative-PCR with housekeeping genes in rice. Biotechnol. Lett. 25, 1869-1872. doi: 10.1023/A:1026298032009
Köllmer, I., Werner, T., and Schmülling, T. (2011). Ectopic expression of different cytokinin-regulated transcription factor genes of Arabidopsis thaliana alters plant growth and development. Plant Physiol. 168, 1320-1327. doi: 10.1016/j.jplph.2011.02.006

Le, D. T., Nishiyama, R., Watanabe, Y., Mochida, K., Yamaguchi-Shinozaki, K., Shinozaki, K., et al. (2011). Genome-wide survey and expression analysis of the plant-specific NAC transcription factor family in soybean during development and dehydration stress. DNA Res. 18, 263-276. doi: 10.1093/dnares/dsr015

Li, M. Y., Wang, F., Jiang, Q., Ma, J., and Xiong, A. S. (2014a). Identification of SSRs and differentially expressed genes in two cultivars of celery (Apium graveolens L.) by deep transcriptome sequencing. Horticult. Res. 1:10. doi: 10.1038/hortres.2014.10

Li, M. Y., Wang, F., Xu, Z. S., Jiang, Q., Ma, J., Tan, G. F., et al. (2014b). High throughput sequencing of two celery varieties small RNAs identifies microRNAs involved in temperature stress response. BMC Genomics 15:242. doi: 10.1186/1471-2164-15-242

Li, Q. F., Sun, S. S. M., Yuan, D. Y., Yu, H. X., Gu, M. H., and Liu, Q. Q. (2010). Validation of candidate reference genes for the accurate normalization of realtime quantitative RT-PCR data in rice during seed development. Plant Mol. Biol. Rep. 28, 49-57. doi: 10.1007/s11105-009-0124-1

Libault, M., Thibivilliers, S., Bilgin, D. D., Radwan, O., Benitez, M., Clough, S. J. et al. (2008). Identification of four soybean reference genes for gene expression normalization. Plant Genome 1, 44-54. doi: 10.3835/plantgenome2008. 02.0091

Liu, X., Dinh, T. T., Li, D., Shi, B., Li, Y., Cao, X., et al. (2014). AUXIN RESPONSE FACTOR 3 integrates the functions of AGAMOUS and APETALA2 in floral meristem determinacy. Plant J. 80, 629-641. doi: 10.1111/tpj.12658

Long, X. Y., Wang, J. R., Ouellet, T., Rocheleau, H., Wei, Y. M., Pu, Z. E., et al. (2010). Genome-wide identification and evaluation of novel internal control genes for Q-PCR based transcript normalization in wheat. Plant Mol. Biol. 74, 307-311. doi: 10.1007/s11103-010-9666-8

Mackay, I. M. (2004). Real-time PCR in the microbiology laboratory. Clin. Microbiol. Infect. 10, 190-212. doi: 10.1111/j.1198-743X.2004.00722.x

Mascia, T., Santovito, E., Gallitelli, D., and Cillo, F. (2010). Evaluation of reference genes for quantitative reverse-transcription polymerase chain reaction normalization in infected tomato plants. Mol. Plant Pathol. 11, 805-816. doi: 10.1111/j.1364-3703.2010.00646.x

Mortazavi, A., Williams, B. A., McCue, K., Schaeffer, L., and Wold, B. (2008). Mapping and quantifying mammalian transcriptomes by RNA-Seq. Nat. Methods 5, 621-628. doi: 10.1038/nmeth.1226

Pfaffl, M. W. (2001). A new mathematical model for relative quantification in real-time RT-PCR. Nucleic Acids Res. 29:e45. doi: 10.1093/nar/29.9.e45

Pfaffl, M. W., Tichopad, A., Prgomet, C., and Neuvians, T. P. (2004). Determination of stable housekeeping genes, differentially regulated target genes and sample integrity, BestKeeper-Excel-based tool using pair-wise correlations. Biotechnol. Lett. 26, 509-515. doi: 10.1023/B:BILE.0000019559.84305.47

Radonić, A., Thulke, S., Mackay, I. M., Landt, O., Siegert, W., and Nitsche, A. (2004). Guideline to reference gene selection for quantitative real-time PCR. Biochem. Biophys. Res. Commun. 313, 856-862. doi: 10.1016/j.bbrc.2003.11.177

Ramakers, C., Ruijter, J. M., Deprez, R. H. L., and Moorman, A. F. M. (2003). Assumption-free analysis of quantitative real-time polymerase chain reaction (PCR) data. Neurosci. Lett. 339, 62-66. doi: 10.1016/S0304-3940(02)01423-4

Reid, K. E., Olsson, N., Schlosser, J., Peng, F., and Lund, S. T. (2006). An optimized grapevine RNA isolation procedure and statistical determination of reference genes for real-time RT-PCR during berry development. BMC Plant Biol. 6:27. doi: 10.1186/1471-2229-6-27

Rounsley, S. D., Ditta, G. S., and Yanofsky, M. F. (1995). Diverse roles for MADS box genes in Arabidopsis development. Plant Cell 7, 1269. doi: 10.1105/tpc.7.8.1259

Saini, S., Sharma, I., Kaur, N., and Pati, P. K. (2013). Auxin, a master regulator in plant root development. Plant Cell Rep. 32, 741-757. doi: 10.1007/s00299-0131430-5

Schippers, J. H. M., and Mueller-Roeber, B. (2010). Ribosomal composition and control of leaf development. Plantence 179, 307-315. doi: 10.1016/j.plantsci.2010.06.012

Schmid, H., Cohen, C. D., Henger, A., Irrgang, S., Schlöndorff, D., and Kretzler, M. (2003). Validation of endogenous controls for gene expression analysis 
in microdissected human renal biopsies. Kidney Int. 64, 356-360. doi: 10.1046/j.1523-1755.2003.00074.x

Tian, C., Jiang, Q., Wang, F., Wang, G. L., Xu, Z., and Xiong, A. S. (2015). Selection of suitable reference genes for qPCR normalization under abiotic stresses and hormone stimuli in carrot leaves. PLOS ONE 10:e0117569. doi: 10.1371/journal.pone.0117569

Udvardi, M. K., Czechowski, T., and Scheible, W. R. (2008). Eleven golden rules of quantitative RT-PCR. Plant Cell 20, 1736-1737. doi: 10.1105/tpc.108.061143

Vandesompele, J., De Preter, K., Pattyn, F., Poppe, B., Von Roy, N., De Paepe, A., and Speleman, F. (2002). Accurate normalization of real-time quantitative RTPCR data by geometric averaging of multiple internal control genes. Genome Biol. 3:research0034. doi: 10.1186/gb-2002-3-7-research0034

Volkov, R. A. (2003). Heat-stress-dependency and developmental modulation of gene expression, the potential of house-keeping genes as internal standards in mRNA expression profiling using real-time RT-PCR. J. Exp. Bot. 54, 2343-2349. doi: $10.1093 /$ jxb/erg244

Wang, H., Chen, S., Jiang, J., Zhang, F., and Chen, D. (2015). Reference gene selection for cross-species and cross-ploidy level comparisons in Chrysanthemum spp. Sci. Rep. 5:8094. doi: 10.1038/srep08094

Wang, H., Wang, J., Jiang, J., Chen, S., Guan, Z., Liao, Y., et al. (2014). Reference genes for normalizing transcription in diploid and tetraploid Arabidopsis. Sci. Rep. 4, 6781-6781. doi: 10.1038/srep06781
Yan, J., Yuan, F., Long, G., Qin, L., and Deng, Z. (2012). Selection of reference genes for quantitative real-time RT-PCR analysis in citrus. Mol. Biol. Rep. 39, 1831-1838. doi: 10.1007/s11033-0110925-9

Yan, J., Yu, L., Xu, S., Gu, W. H., and Zhu, W. M. (2014). Apigenin accumulation and expression analysis of apigenin biosynthesis relative genes in celery. Sci. Hortic. s165, 218-224. doi: 10.1016/j.scienta.2013. 11.018

Zhu, J., He, F., Song, S., Wang, J., and Yu, J. (2008). How many human genes can be defined as housekeeping with current expression data? BMC Genomics 9:172. doi: 10.1186/1471-2164-9-172

Conflict of Interest Statement: The authors declare that the research was conducted in the absence of any commercial or financial relationships that could be construed as a potential conflict of interest.

Copyright (c) 2016 Li, Wang, Jiang, Wang, Tian and Xiong. This is an open-access article distributed under the terms of the Creative Commons Attribution License (CC $B Y)$. The use, distribution or reproduction in other forums is permitted, provided the original author(s) or licensor are credited and that the original publication in this journal is cited, in accordance with accepted academic practice. No use, distribution or reproduction is permitted which does not comply with these terms. 